Article

\title{
Improving of the Photovoltaic Characteristics of Dye-Sensitized Solar Cells Using a Photoelectrode with Electrospun Porous $\mathrm{TiO}_{2}$ Nanofibers
}

\author{
Min Su Jo ${ }^{1}$, Jung Sang Cho ${ }^{1, * \mathbb{D}}$, Xuan Liang Wang ${ }^{2}$, En Mei Jin ${ }^{2, *}$, Sang Mun Jeong ${ }^{2, *}$ and \\ Dong-Won Kang ${ }^{3}$ \\ 1 Department of Engineering Chemistry, Chungbuk National University, 1 Chungdae-ro, Seowon-Gu, \\ Cheongju, Chungbuk 28644, Korea; jms039@naver.com \\ 2 Department of Chemical Engineering, Chungbuk National University, 1 Chungdae-ro, Seowon-Gu, \\ Cheongju, Chungbuk 28644, Korea; wangxuanleon@gmail.com \\ 3 School of Energy Systems Engineering, Chung-Ang University, Seoul 06974, Korea; kangdwn@cau.ac.kr \\ * Correspondence: jscho@chungbuk.ac.kr (J.S.C.); jinenmei@chungbuk.ac.kr (E.M.J.); \\ smjeong@chungbuk.ac.kr (S.M.J.); Tel.: +82-43-261-2489 (J.S.C.); +82-70-8667-0097 (E.M.J.); \\ +82-43-261-3369 (S.M.J.)
}

Received: 11 December 2018; Accepted: 8 January 2019; Published: 12 January 2019

\begin{abstract}
Porous $\mathrm{TiO}_{2}$ nanofibers (PTFs) and dense $\mathrm{TiO}_{2}$ nanofibers (DTFs) were prepared using simple electrospinning for application in dye-sensitized solar cells (DSSCs). $\mathrm{TiO}_{2}$ nanoparticles (TNPs) were prepared using a hydrothermal reaction. The as-prepared PTFs and DTFs (with a fiber diameter of around $200 \mathrm{~nm}$ ) were mixed with TNPs such as TNP-PTF and TNP-DTF nanocomposites used in photoelectrode materials or were coated as light scattering layers on the photoelectrodes to improve the charge transfer ability and light harvesting effect of the DSSCs. The as-prepared TNPs showed a pure anatase phase, while the PTFs and DTFs showed both the anatase and rutile phases. The TNP-PTF composite (TNP:PTF = 9:1 wt.\%) exhibited an enhanced short circuit photocurrent density $\left(J_{s c}\right)$ of $14.95 \pm 1.03 \mathrm{~mA} \mathrm{~cm}{ }^{-2}$ and a photoelectric conversion efficiency (PCE, $\eta$ ) of $5.4 \pm$ $0.17 \%$ because of the improved charge transport and accessibility for the electrolyte ions. In addition, the TNP/PTF photoelectrode showed excellent light absorption in the visible region because of the mountainous nature of light induced by the PTF light scattering layer. The TNP/PTF photoelectrode showed the highest $J_{s c}\left(16.96 \pm 0.79 \mathrm{~mA} \mathrm{~cm}^{-2}\right), \eta(5.9 \pm 0.13 \%)$, and open circuit voltage $\left(V_{o c}, 0.66 \pm\right.$ $0.02 \mathrm{~V})$.
\end{abstract}

Keywords: electrospinning; nanocomposites; porous $\mathrm{TiO}_{2}$ nanofiber; light harvesting; additive; dye-sensitized solar cells

\section{Introduction}

Dye-sensitized solar cells (DSSCs) are basically thin-layer solar cells consisting of two sandwichtype transparent conduction oxide (TCO) electrodes. One electrode is a highly colored photoelectrode with a few micron-thick layers of mesoporous $\mathrm{TiO}_{2}$ or other semiconductors $\left(\mathrm{ZnO}, \mathrm{SnO}_{2}\right.$, and $\left.\mathrm{Nb}_{2} \mathrm{O}_{5}\right)$ coated with a photosensitizer, while the other is a Pt-based counter-electrode [1-5]. The space between the two electrodes is filled with an organic electrolyte containing a redox mediator $\left(\mathrm{I}^{-} / \mathrm{I}_{3}{ }^{-}\right)$, usually a mixture of iodine and iodide in organic solvents such as acetonitrile [6-10]. DSSCs, which are cost-effective and have high theoretical efficiencies, are available in various colors depending on the dye. DSSCs co-photosensitized with an organic dye of alkoxysilyl-anchor dye (ADEKA-1, molecular structures of carbazole dyes with a trimethoxysilyl group) and a carboxy-anchor organic dye of LEG4 anchored to nanocrystalline $\mathrm{TiO}_{2}$ films show a photoelectric conversion efficiency (PCE) of 
up to $14.7 \%$ (under 1 sun illumination) [11]. The theoretical PCE limit of DSSCs using a simple junction configuration (under standard test conditions) is reported to be 33\% [12,13]. However, the PCE of present DSSCs is significantly lower than their theoretical efficiency. The PCE response of DSSCs depends on their open circuit voltage $\left(V_{o c}, \mathrm{~V}\right)$, photocurrent density $\left(J_{s c}, \mathrm{~mA} \mathrm{~cm}^{-2}\right)$, and fill factor $(F F, \%)[14,15]$. The $V_{o c}$ is estimated from the difference between the quasi-Fermi levels of semiconductor materials, such as $\mathrm{TiO}_{2}$, and the redox potential of the electrolyte $\left(\mathrm{I}^{-} / \mathrm{I}_{3}{ }^{-}\right)$. Therefore, the $V_{o c}$ of DSSCs is closely related to the properties of the semiconductor materials constituting them. The $J_{S c}$ and FF of DSSCs depend on the adsorption of the dye and the charge transfer in the photoelectrode [15-17].

$\mathrm{TiO}_{2}$ typically used for a photoelectrode is chemically stable, non-toxic, and readily available in vast quantities [18-22]. For the enhanced photovoltaic properties of $\mathrm{TiO}_{2}$ for DSSC, it is imperative to improve its surface area, dye molecular adsorption activity, light harvesting effect, and charge transport. There have been many reports on the use of metal oxide additives, such as $\mathrm{SiO}_{2}, \mathrm{SnO}_{2}$, and $\mathrm{ZrO}_{2}$, for improving the photovoltaic properties of $\mathrm{TiO}_{2}$ nanoparticles [23-25]. In our previous study [26], $\mathrm{SnO}_{2}$ hollow fibers were used as the additives for the $\mathrm{TiO}_{2}$ photoelectrodes in order to improve the electron transport of DSSCs. The addition of $\mathrm{SnO}_{2}$ hollow fibers accelerated the electron transfer and improved the electrochemical properties of the DSSC. The PCE of the DSSC with the $\mathrm{SnO}_{2}$ hollow fiber-added $\mathrm{TiO}_{2}$ photoelectrode was approximately $11 \%$ higher $(5.43 \%)$ than that of the DSSC with pure $\mathrm{TiO}_{2}$ photoelectrode $(4.89 \%)$. Swathy et al. [27] used nanostructured $(\approx 400$ nm particle size $)$ anatase titania spheres as the light scattering layer for DSSCs. These DSSCs showed about two times higher $J_{S C}\left(10.44 \mathrm{~mA} \mathrm{~cm}^{-2}\right)$ and two times higher PCE $(4.92 \%)$ than those of $\mathrm{TiO}_{2}$ photoelectrodes without scattering layers $\left(J_{s c}\right.$ of $5.83 \mathrm{~mA} \mathrm{~cm}^{-2}$, PCE of $\left.2.7 \%\right)$. The photovoltaic performance of the DSSCs was measured under an AM1.5G solar spectrum with a light intensity of $100 \mathrm{~mW} \mathrm{~cm}^{-2}$.

In summary, the PCE of DSSCs can be easily improved by altering the design of their photoelectrodes. In this study, we prepared seven $\mathrm{TiO}_{2}$ photoelectrodes to improve the PCE of DSSCs, as shown in Scheme 1. The $\mathrm{TiO}_{2}$ photoelectrodes were fabricated using $\mathrm{TiO}_{2}$ nanoparticles and the porous $\mathrm{TiO}_{2}$ nanofibers (PTFs), and dense $\mathrm{TiO}_{2}$ nanofibers (DTFs) were used as additives or light scattering layer. The PTFs and DTFs were prepared using simple electrospinning. $\mathrm{TiO}_{2}$ nanoparticles (TNPs) were prepared using a hydrothermal reaction and were used for fabricating the photoelectrodes. The as-prepared PTFs and DTFs were used as additives or were coated as light scattering layers to improve the charge transfer ability and light harvesting effect of the DSSCs.

\section{Materials and Methods}

\subsection{Preparation of Porous $\mathrm{TiO}_{2}$ Nanofibers (PTFs)}

The porous $\mathrm{TiO}_{2}$ nanofibers (PTF) were prepared via an electrospinning process and subsequent heat treatment. The spinning solution was prepared by adding $2 \mathrm{~mL}$ butyl titanate $\left(\mathrm{TBT}, \mathrm{C}_{16} \mathrm{H}_{36} \mathrm{O}_{4} \mathrm{Ti}_{\text {, }}\right.$ $\geq 97 \%$, Kanto Chemical Co. Inc, Tokyo, Japan), 1 g polyacrylonitrile (PAN, Mw: 150,000, Sigma-Aldrich, St. Louis, MO, USA), 4 g polystyrene (PS, Mw: $\approx 192,000$, Sigma-Aldrich), and $2 \mathrm{~mL}$ of acetic acid (99.7\%, Daejung Chemicals and Metals, Siheung, Korea) in $40 \mathrm{~mL}$ of N,N-dimethylformamide (DMF, $\geq 99.5 \%$, Samchun Chemical, Seoul, Korea). The resulting solution was stirred at room temperature for $24 \mathrm{~h}$ to ensure complete dissolution and was then loaded into a plastic syringe equipped with a $25 \mathrm{G}$ stainless steel needle $\left(\varnothing_{\text {in }}=0.25 \mathrm{~mm}, \varnothing_{\text {out }}=0.51 \mathrm{~mm}\right)$. The needle was connected to a high-voltage supply and a voltage of $20 \mathrm{kV}$ was applied between the needle and the collector. The distance between the needle tip and the drum collector was set at $15 \mathrm{~cm}$ at a flow rate of $2 \mathrm{~mL} \mathrm{~h}^{-1}$. The rotation of the drum was maintained at $150 \mathrm{rpm}$. The resulting electrospun fibers were heated at $100{ }^{\circ} \mathrm{C}$ in air for $6 \mathrm{~h}$ to remove the solvent, and then heat-treated at $500{ }^{\circ} \mathrm{C}$ for $3 \mathrm{~h}$ (heating rate was $5{ }^{\circ} \mathrm{C} \min ^{-1}$ ) in air to remove the polymer. 


\subsection{Preparation of Dense $\mathrm{TiO}_{2}$ Nanofibers (DTFs)}

The dense $\mathrm{TiO}_{2}$ nanofibers (DTF) were also prepared via an electrospinning process and subsequent heat treatment. The spinning solution was prepared by adding $4 \mathrm{~mL} \mathrm{TBT,} 2 \mathrm{~g}$ polyvinylpyrrolidone (PVP, M.W. 1,300,000, Alfa Aesar, Haverhill, MA, USA), and $8 \mathrm{~mL}$ of acetic acid in $20 \mathrm{~mL}$ of ethanol (99.7\%, Daejung Chemicals and Metals, Siheung, Korea). The resulting solution was electrospun and heat-treated under the same condition as described above for PTF.

\subsection{Preparation of Anatage $\mathrm{TiO}_{2}$ Nanoparticles (TNPs)}

TNPs were synthesized via the hydrothermal method. In a typical reaction, $15 \mathrm{~mL}$ of titanium tetraisopropoxide (TTIP, 99.9\%, Aldrich) was dissolved in $50 \mathrm{~mL}$ of distilled water and the resulting solution was vigorously stirred for a few minutes before adding $0.7 \mathrm{~mL}$ of ammonia solution $(28-30 \%$, SAMCHUN) to it. This solution was magnetically stirred at $350 \mathrm{rpm}$ for $3 \mathrm{~h}$ to obtain a homogeneous mixture. The reaction mixture so obtained was transferred to a Teflon-lined autoclave and was then heated at $200{ }^{\circ} \mathrm{C}$ for $5 \mathrm{~h}$. Finally, the white precipitate was washed with distilled water and ethanol and then dried at $80^{\circ} \mathrm{C}$ for $12 \mathrm{~h}$.

\subsection{Preparation of DSSCs}

$\mathrm{TiO}_{2}$ photoelectrodes were fabricated using TNP or TNP-DTF or TNP-PTF nanocomposites. The $\mathrm{TiO}_{2}$ pastes were prepared by mixing acetylacetone (99\%, Sigma-Aldrich), hydroxypropyl cellulose (99\%, Aldrich), and distilled water. Each paste was coated on a fluorine-doped tin oxide $\left(8 \Omega\right.$ /sq, Pilkington) substrate, which was subsequently sintered at $450{ }^{\circ} \mathrm{C}$ for $30 \mathrm{~min}$. The obtained $\mathrm{TiO}_{2}$ films were immersed in a $0.5 \mathrm{mM}$ ethanol solution of N719 dye (bis-(isothiocyanato)bis (2,2-bipyridyl-4,4-dicarboxylato)ruthenium(II)bis-tetrabutylammonium, Solaronix) for $5 \mathrm{~h}$. The active area of the photoelectrode was $0.25 \mathrm{~cm}^{2}$. The sandwich-type DSSC was assembled using a Pt counter-electrode and a dye-sensitized photoelectrode. A redox $\mathrm{I}^{-} / \mathrm{I}_{3}{ }^{-}$electrolyte was introduced between the electrodes. The preparation methods of the counter electrode and $\mathrm{I}^{-} / \mathrm{I}_{3}{ }^{-}$electrolyte were described in detail in our previous report [17].

In this study, we prepared seven kinds of photoelectrodes, as shown in Scheme 1. The photoelectrodes with only TNP, PTFs, and DTFs were labeled as TNP, PTF, and DTF, respectively. The TNP photoelectrodes with $10 \mathrm{wt} . \%$ of PTFs and DTFs were denoted as TNP-PTF and TNP-DTF, respectively. The photoelectrodes with PTF and DTF light scattering layers were denoted as TNP/PTF and TNP/DTF, respectively.

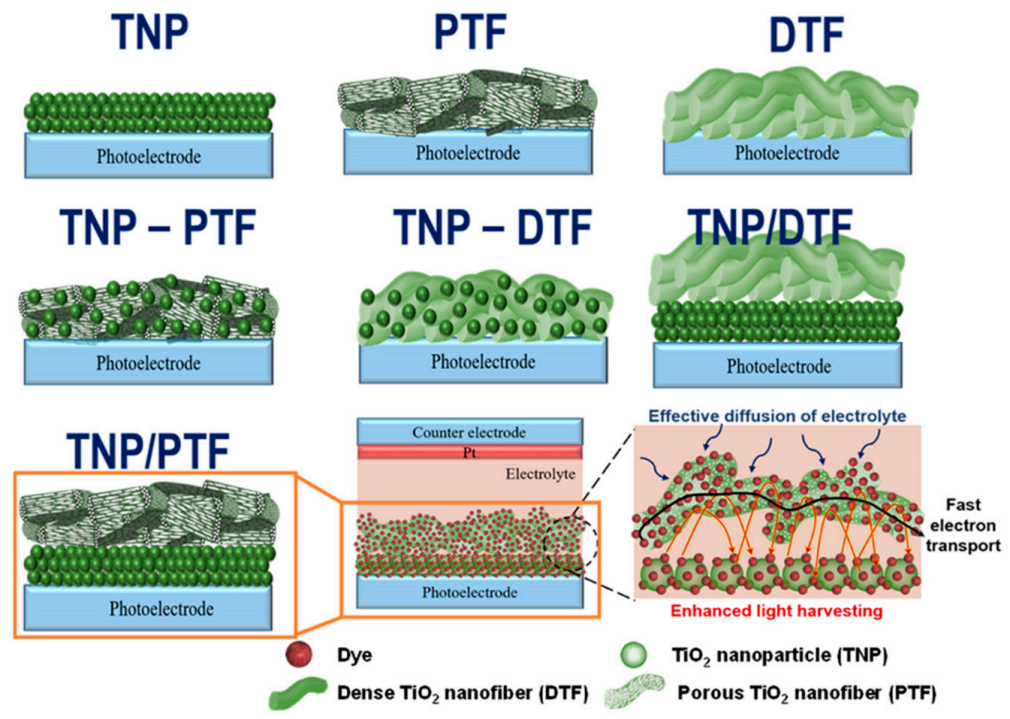

Scheme 1. Various photoelectrodes for DSSCs. 


\subsection{Characteristic and Measurements}

The crystalline phases and morphologies of the prepared materials were identified using X-ray diffraction (XRD, Ultima IV, Rigaku, Japan), field-emission scanning electron microscopy (FE-SEM; LEO-1530, Carl Zeiss, Oberkochen, Germany), and field-emission transmission electron microscopy (FE-TEM, 200KV, JEM 2100F, JEOL, Tokyo, Japan). To estimate the specific surface area, pore volume, and pore size distribution of the materials, and their $\mathrm{N}_{2}$ adsorption/desorption isotherms were measured at $77 \mathrm{~K}$ using a surface area analyzer (ASAP2020, Micromeritics, Norcross, GA, USA). The Brunauer-Emmett-Teller (BET) method and Barrett-Joyner-Halenda (BJH) model were used to estimate the specific surface area and pore size distribution of the samples, respectively. Ultraviolet-visible (UV-Vis-NIR) reflectance spectra were obtained using a UV-Vis-NIR spectrophotometer (Cary 5G, Varian, Palo Alto, CA, USA) equipped with diffuse reflectance accessory (integral sphere). Total reflectance spectrum (Total reflectance $=$ Diffuse reflectance + Specular reflectance) was recorded in the spectral range of 200 to $800 \mathrm{~nm}$ at a scan rate of $600 \mathrm{~nm} \mathrm{~min}-1$. In addition, the UV-Vis spectrum of N719 solution was measured using S-3100 equipment (Sinco, Seoul, Korea). The photovoltaic properties of the DSSCs were evaluated by recording their current density-voltage characteristics under illumination from a Polaronix K201 (McScience, Suwon, Korea) equipped with a K401 CW150 lamp power supply and an AM 1.5G filter $\left(100 \mathrm{~mW} \mathrm{~cm}^{-2}\right)$.

\section{Results}

The morphological features of PTFs, DTFs, and TNPs were observed by FE-SEM and FE-TEM, as shown in Figure 1. Figure 1a shows PTF prepared using a spinning process, in which numerous pores in the structure were confirmed from the fiber surface and cross-sectioned inset image. The PS in the spinning solution was separated with PAN during electrospinning. Subsequently, PS in the as-spun fibers was decomposed into $\mathrm{CO}_{2}$ gas during heat treatment, which formed the numerous pores between $\mathrm{TiO}_{2}$ crystals in the structure. On the other hand, DTF fibers prepared from the solution without PS showed dense structure in Figure 1b. Without the effect of phase separation by adding PS, pores were not generated in the structure. Therefore, it was hard to observe any pores, even in the cross-sectioned inset image in Figure 1b. The mean fiber diameter of PTF and DTF measured from FE-TEM images were both $200 \mathrm{~nm}$. From the elemental mapping images in Figure 1d,e, both $\mathrm{TiO}_{2}$ nanofibers showed uniformly distributed $\mathrm{Ti}$ and $\mathrm{O}$ elements over the nanostructure, but the $\mathrm{C}$ element was negligible, which proves the completely decomposition of $C$ during heat treatment. The TNPs were rice-shaped and had an average particle size of about $30 \mathrm{~nm}$ (Figure 1c). Figure $1 \mathrm{~d}-\mathrm{f}$ shows the FETEM and EDX mapping results of the PTF, DTF, and TNP powders. The EDX mapping results show that only $\mathrm{Ti}$ and $\mathrm{O}$ were present in the samples. $\mathrm{C}$ was detected on the carbon tape used for the sampling. The EDX results also showed that the PTFs were less dense as compared to the DTFs. BET surface area measurements were carried out to determine the pore diameters and surface areas of the samples quantitatively.

The pore diameter and surface areas of the PTFs, DTFs, and TNPs were measured by carrying out BET measurements. The pore distribution and diameter determine the fast charge transfer and light harvesting effect of porous fibers. However, a fiber structure is not good for the adsorption of light-absorbing dyes. Adsorption of dye molecules is closely related to the specific surface area of photoelectrode materials. Hence, in this study, we fabricated various photoelectrodes using the TNPs, PTFs, and DTFs. The TNP, PTF, DTF, TNP-PTF, TNP-DTF, TNP/PTF, and TNP/DTF photoelectrodes were used to assemble DSSCs. The photovoltaic properties of these DSSCs were investigated. Figure 2 shows the cross-section and top view of the TNP/PTF, TNP/DTF, and TNP photoelectrodes. The thickness of the TNP photoelectrode was about $8 \pm 0.6 \mu \mathrm{m}$ and the PTF and DTF light scattering layers were coated on it. The top-view of TNP/PTF and TNP/DTF (Figure 2c,d) revealed that TNP/PTF showed porosity and a loofah-like formation. These pores could improve the light-harvesting and electrolyte diffusion of the photoelectrode and hence improved the charge transport and accessibility of the electrolyte ions [28-31]. 

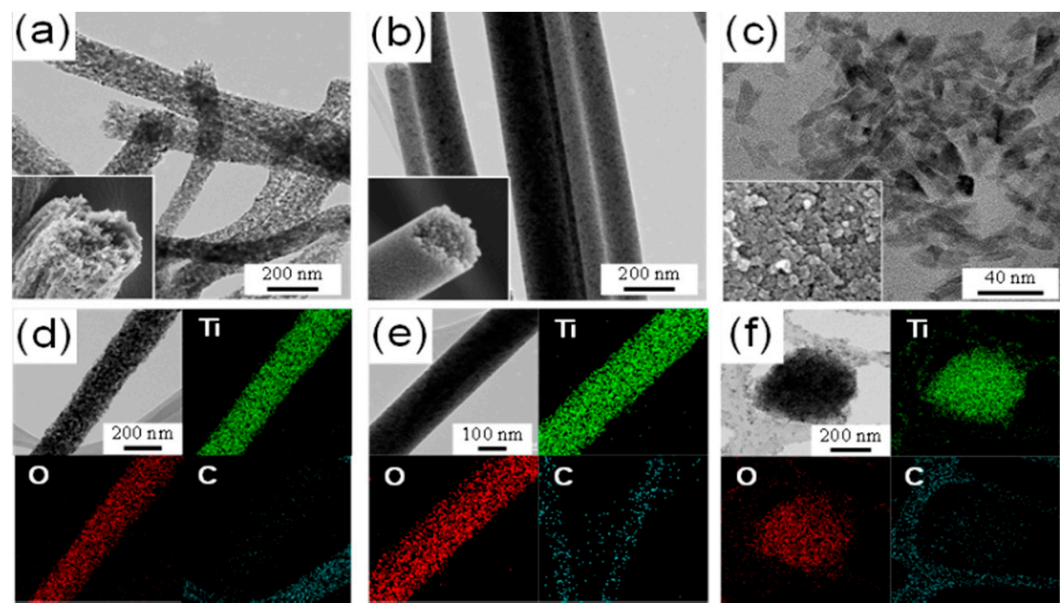

Figure 1. FESEM and FETEM images of the (a) PTF, (b) DTF, and (c) TNP powders. FETEM and EDX mapping of the (d) PTF, (e) DTF, and (f) TNP powders.
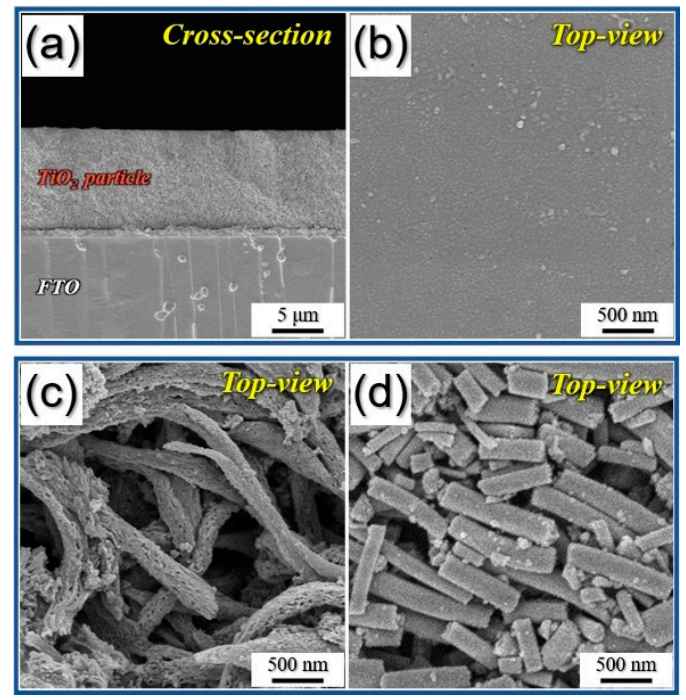

Figure 2. FESEM images of the (a) cross-section view of the TNP photoelectrode, and top-view of the (b) TNP, (c) TNP/PTF and (d) TNP/DTF photoelectrodes.

$\mathrm{N}_{2}$ adsorption of all the samples was carried out and the results are shown in Figure 3 and Table 1. The TNPs exhibited a specific surface area of $140 \mathrm{~m}^{2} \mathrm{~g}^{-1}$. The surface areas of the PTFs and DTFs were lower than that of the TNPs. The TNPs, PTFs, and DTPs showed type-IV adsorption isotherms, indicating the presence of mesoporous structures with an average pore size of 7.13, 18.47, and $5.48 \mathrm{~nm}$, respectively. In the case of the TNPs, the hysteresis loop was more prominent for the relative pressures $\left(\mathrm{P} / \mathrm{P}_{0}\right)$ in the range of $0.7-1.0$, indicating the presence of many pores. Figure $3 \mathrm{~b}$ shows the pore diameter distribution of the samples (within 0-100 nm). The PTFs showed a large mesopore volume of $10-50 \mathrm{~nm}$. They exhibited a hierarchical pore structure consisting mainly of mesopores along with some micropores. Therefore, the use of PTF photoelectrodes can improve the electrode-electrolyte interactions and shorten the ionic transport paths, thus promoting the charge transport and enhancing the accessibility for electrolyte ions. 

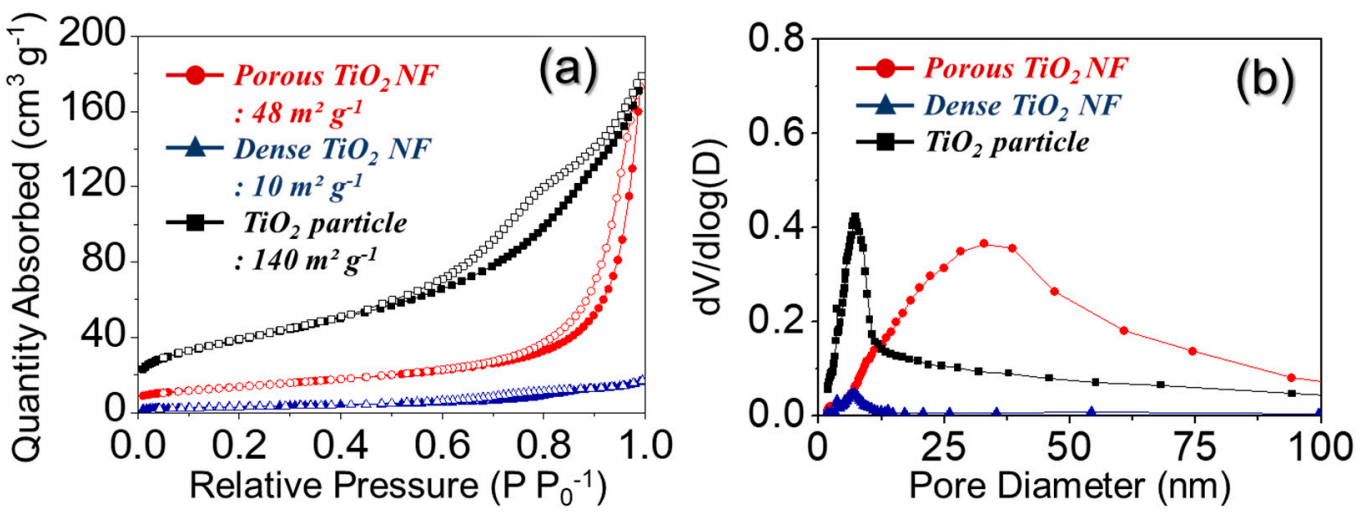

Figure 3. (a) $\mathrm{N}_{2}$ adsorption isotherms and (b) pore-size distribution of the PTF, DTF, and TNP powders.

Table 1. BET and crystal structure of the TNP, PTF, and DTF powders and the photovoltaic parameters of different photoelectrode used DSSC.

\begin{tabular}{|c|c|c|c|c|c|c|c|c|}
\hline $\begin{array}{c}\text { Photo- } \\
\text { Electrodes }\end{array}$ & $\begin{array}{c}\text { BET } \\
\left(\mathrm{m}^{2} \mathrm{~g}^{-1}\right)\end{array}$ & $\begin{array}{c}\text { Pore Size } \\
(\mathrm{nm})\end{array}$ & $\begin{array}{l}\text { Pore Volume } \\
\left(\mathrm{cm}^{3} \mathrm{~g}^{-1}\right)\end{array}$ & $\begin{array}{c}\text { Crystal } \\
\text { Structure }\end{array}$ & $V_{o c}(\mathrm{~V})$ & $\begin{array}{c}J_{s c} \\
\left(\mathrm{~mA} \mathrm{~cm} \mathrm{~cm}^{-2}\right)\end{array}$ & $F F(\%)$ & $\eta(\%)$ \\
\hline TNP & 140.08 & 7.13 & 0.2763 & Anatase & $0.69 \pm 0.02$ & $12.51 \pm 0.60$ & $53 \pm 2$ & $4.6 \pm 0.07$ \\
\hline PTF & 48.01 & 18.47 & 0.2794 & $\begin{array}{c}\text { Anatase, } \\
\text { Rutile }\end{array}$ & $0.65 \pm 0.01$ & $10.30 \pm 0.96$ & $56 \pm 2$ & $3.8 \pm 0.19$ \\
\hline DTF & 23.16 & 5.48 & 0.0460 & $\begin{array}{l}\text { Anatase, } \\
\text { Rutile }\end{array}$ & $0.66 \pm 0.01$ & $10.18 \pm 1.24$ & $48 \pm 7$ & $3.2 \pm 0.15$ \\
\hline TNP-PTF & - & - & - & - & $0.68 \pm 0.01$ & $14.95 \pm 1.03$ & $54 \pm 2$ & $5.4 \pm 0.17$ \\
\hline TNP-DTF & - & - & - & - & $0.68 \pm 0.01$ & $13.42 \pm 0.50$ & $55 \pm 1$ & $5.1 \pm 0.16$ \\
\hline $\mathrm{TNP} / \mathrm{PTF}$ & - & - & - & - & $0.66 \pm 0.02$ & $16.96 \pm 0.79$ & $56 \pm 2$ & $5.9 \pm 0.13$ \\
\hline TNP/DTF & - & - & - & - & $0.66 \pm 0.01$ & $14.39 \pm 0.50$ & $54 \pm 1$ & $5.2 \pm 0.13$ \\
\hline
\end{tabular}

The structural properties of the PTF, DTF, and TNP powders were investigated using their XRD patterns shown in Figure 4. The PTFs and DTFs showed mixed anatase (space group I41/amd, card no. 21-1272 in the JCPDS database) and rutile (card no. 21-1276 in the JCPDS database) phases. On the other hand, the TNPs showed only the anatase phase [32,33]. The dark and white squares in Figure 4 correspond to the anatase and rutile phases, respectively. The XRD results showed that the rutile phase fraction of the DTFs (rutile phase peak intensity was higher) was higher than that of the PTF. The rutile phase has a slightly lower bandgap than the anatase phase and can absorb a little sunlight in the near-UV region. The open-circuit voltage of DSSCs can be controlled by adjusting the position of the $\mathrm{TiO}_{2}$ conduction band. Most of the studies in this context have focused on anatase $\mathrm{TiO}_{2}$. However, rutile $\mathrm{TiO}_{2}$ is easy to produce and has superior light-scattering properties, which is beneficial for effective light-harvesting [34]. Therefore, we used the PTFs and DTFs (which consisted of the rutile phase) as light scattering layers for DSSCs.
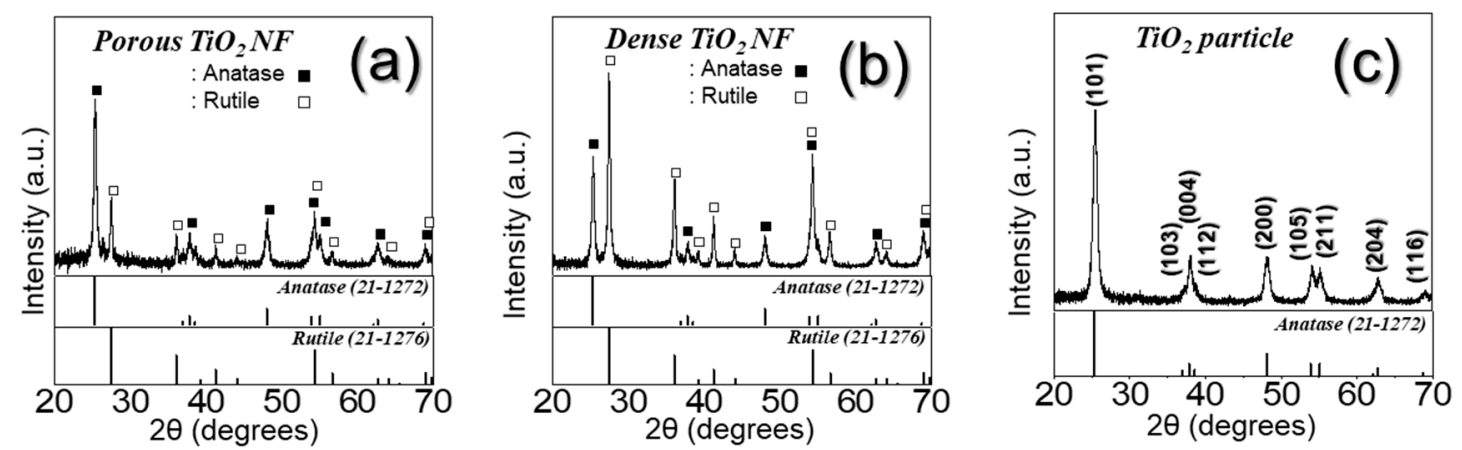

Figure 4. X-ray diffraction of the (a) PTF, (b) DTF, and (c) TNP powders.

Figure 5 shows the photocurrent density-voltage curves of the DSSCs fabricated using different photoelectrodes. As shown in Figure 5, the TNP photoelectrode showed a higher open-circuit voltage 
$\left(V_{o c}\right)(0.69 \pm 0.02 \mathrm{~V})$ than the PTF and DTF photoelectrodes. The $V_{o c}$ of DSSCs can be controlled by adjusting the position of the $\mathrm{TiO}_{2}$ conduction band. Hence, the $V_{o c}$ of the PTF and DTF photoelectrodes (having the rutile crystalline structure) was lower than that of the anatase TNP photoelectrode. In addition, the photocurrent densities of the PTF and DTF photoelectrodes were lower than that of the TNP photoelectrode because of the loading of a small amount of dye. Dye loading of a photoelectrode is closely related to the specific surface area of $\mathrm{TiO}_{2}$; the larger the specific surface area of $\mathrm{TiO}_{2}$, the larger is the amount of dye that can be adsorbed on the $\mathrm{TiO}_{2}$ surface. The addition of the PTFs and DTFs to the TNP photoelectrodes resulted in an increase in the short circuit photocurrent density $\left(J_{s c}\right)$ and PCE $(\eta)$ because of the improved charge transport and enhanced accessibility for the electrolyte ions. On the other hands in order to improve the light harvesting effect of the DSSCs, the PTF or DTF light scattering layers were coated on the TNP photoelectrodes. As the result, the TNP/PTF photoelectrode showed the highest $J_{s c}$ and $\eta$. The high $J_{s c}$ can be attributed to the increased light harvesting effect due to the PTF light-scattering layer. The rutile phase-mixed PTF acted as an energy barrier and increased the physical separation between the injected electrons and oxidized dyes/redox couples, thereby retarding the recombination reactions in the resulting DSSCs [35]. The detailed photocurrent density-voltage results are given in Table 1. The TNP/PTF photoelectrode-based DSSC showed the highest $\eta$ of $5.9 \pm 0.13 \%$, which is approximately $28 \%$ higher than that of the TNP photoelectrode-based DSSCs $(4.6 \pm 0.07 \%)$.

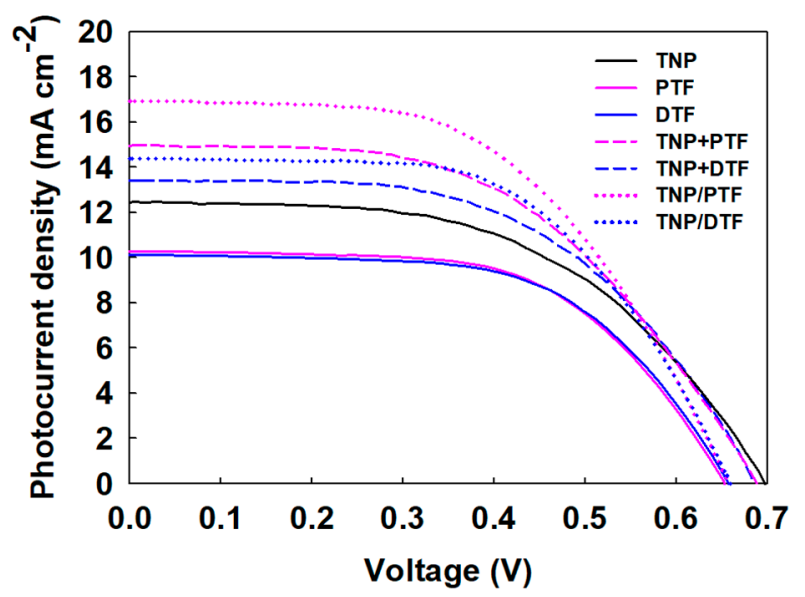

Figure 5. Photocurrent density-voltage curves of the DSSCs with different photoelectrodes.

The UV-Vis absorption spectra of the TNP, TNP/DTF, TNP/PTF photoelectrodes, and N719 dye are shown in Figure 6. As shown in Figure 6a, all the samples showed strong absorption in the UV region (wavelengths lower than $250 \mathrm{~nm}$ ) before dye adsorption. It can be observed that the absorption edges of the TNP/DTF and TNP/PTF photoelectrodes slightly red-shifted with respect to the TNP photoelectrode, suggesting that the TNP/DTF and TNP/PTF photoelectrodes caused a small decrease in the energy band gap. In addition, the TNP/DTF and TNP/PTF photoelectrodes showed an absorption peak in the near-UV region at $330 \mathrm{~nm}$, which can be attributed to their rutile structure. All the samples showed almost no absorption in the visible region. As shown in Figure 6b, the N719 dye showed an absorption peak in the visible region at $530 \mathrm{~nm}$. The intensity of this peak was high in the case of the TNP/PTF photoelectrode. This indicates that the use of the PTF light scattering layer (TNP/PTF) coating increased the visible region absorption of the DSSC. 

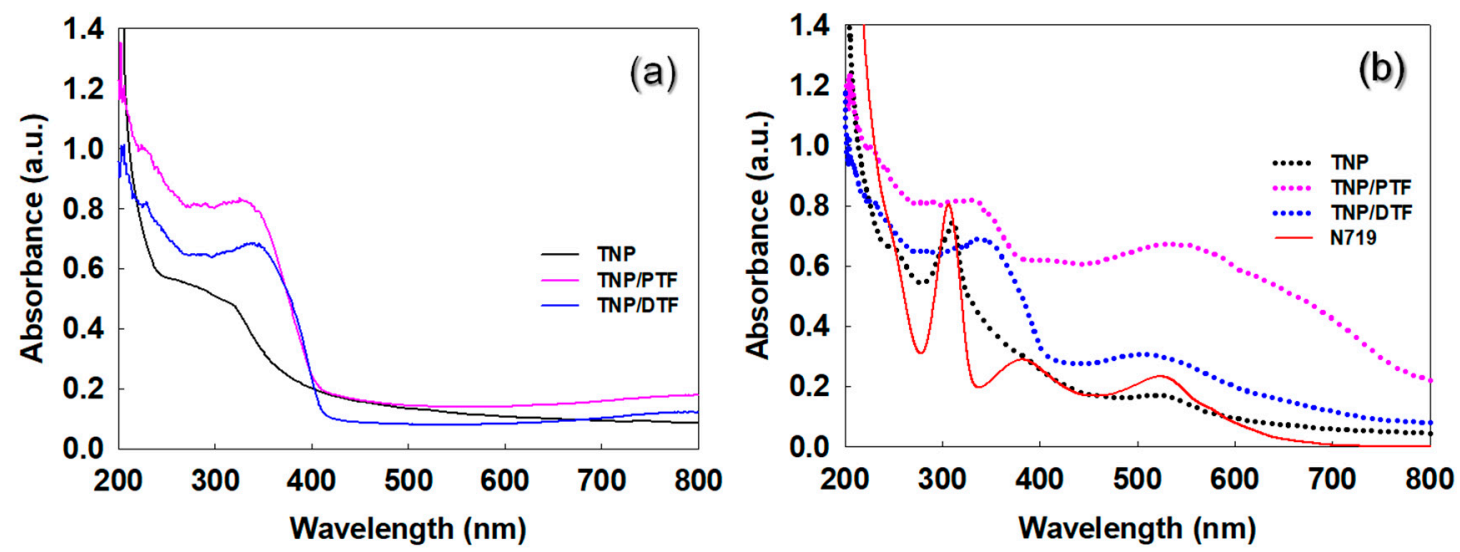

Figure 6. UV-Vis absorption spectra of the different photoelectrodes (a) before and (b) after N719 dye adsorption.

\section{Conclusions}

Porous and dense $\mathrm{TiO}_{2}$ nanofibers (200 nm fiber diameter) were successfully prepared using electrospinning and were used as additives or light-scattering layers to enhance the photovoltaic properties of DSSC. Both the PTFs and DTFs showed mixed phases of anatase and rutile $\mathrm{TiO}_{2}$ crystals. The addition of $10 \mathrm{wt} . \%$ of PTFs or DTFs increased the short circuit photocurrent density $\left(J_{s c}\right)$ of the TNP photoelectrode because of an improvement in the charge transport and accessibility for the electrolyte ions. In addition, the TNP/PTF photoelectrode improved the visible light absorption of the DSSC because of the mountainous nature of light due to the PTF light scattering layer. The highest short circuit photocurrent density was shown by the TNP/PTF photoelectrode $\left(16.96 \pm 0.79 \mathrm{~mA} \mathrm{~cm}^{-2}\right)$. The TNP/PTF photoelectrode showed a high PCE of $5.9 \pm 0.13 \%$ and an open-circuit voltage $\left(V_{o c}\right)$ of $0.66 \pm 0.02 \mathrm{~V}$. These results show that the use of scattering layers made up of PTFs is an effective approach to improve the photovoltaic performance of DSSCs.

Author Contributions: J.S.C. and S.M.J. conceived the overall approach and supervised the project. M.S.J. and X.L.W. performed experiments and E.M.J. designed experiments, analyzed the data, and wrote this manuscript, which was corrected by J.S.C., S.M.J., and D.-W.K.

Funding: Please add: This research was supported by Basic Science Research Program through the National Research Foundation of Korea (NRF) funded by the Korea government (2017R1D1A1B03031989; 2017M1A2A2087577; 2018R1A4A1024691).

Conflicts of Interest: The authors declare no conflict of interest.

\section{References}

1. Tehare, K.K.; Navale, S.T.; Stadler, F.J.; He, Z.; Yang, H.; Xiong, X.; Liu, X.; Mane, R.S. Enhanced DSSCs Performance of $\mathrm{TiO}_{2}$ Nanostructure by Surface Passivation Layers. Mater. Res. Bull. 2018, 99, 491-495. [CrossRef]

2. Giovannetti, R.; Zannotti, M.; Alibabaei, L.; Ferraro, S. Equilibrium and Kinetic Aspects in the Sensitization of Monolayer Transparent $\mathrm{TiO}_{2}$ Thin Films with Porphyrin Dyes for DSSC Applications. Int. J. Photoenergy 2014, 2014, 1-9. [CrossRef]

3. Giannouli, M.; Govatsi, K.; Syrrokostas, G.; Yannopoulos, S.N.; Leftheriotis, G. Factors Affecting the Power Conversion Efficiency in ZnO DSSCs: Nanowire vs. Nanoparticles. Materials 2018, 11, 411. [CrossRef] [PubMed]

4. Kiran, S.; Naveen Kumar, S.K. Preparation and Thickness Optimization of $\mathrm{TiO}_{2} / \mathrm{Nb}_{2} \mathrm{O}_{5}$ Photoanode for Dye Sensitized Solar Cells. Mater. Today 2018, 5, 10797-10804. [CrossRef]

5. Sasikumar, R.; Chen, T.-W.; Chen, S.M.; Rwei, S.-P.; Ramaraj, S.K. Developing the Photovoltaic Performance of Dye-sensitized Solar Cells (DSSCs) Using a $\mathrm{SnO}_{2}$-Doped Graphene Oxide Hybrid Nanocomposite as a Photo-Anode. Opt. Mater. 2018, 79, 345-352. [CrossRef]

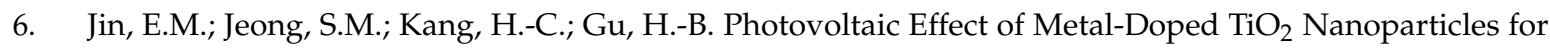
Dye-Sensitized Solar Cells. ECS J. Solid State Sci. Technol. 2016, 5, Q109-Q114. [CrossRef] 
7. Kim, D.-W.; Jeong, Y.-B.; Kim, S.-H.; Lee, D.-Y.; Song, J.-S. Photovoltaic Performance of Dye-Sensitized Solar Cell Assembled with Gel Polymer Electrolyte. J. Power Sources 2005, 149, 112-116. [CrossRef]

8. Palomares, E.; Clifford, J.N.; Haque, S.A.; Lutz, T.; Durrant, J.R. Slow Charge Recombination in Dye-Sensitized Solar Cells (DSSC) Using $\mathrm{Al}_{2} \mathrm{O}_{3}$ Coated Nanoporous $\mathrm{TiO}_{2}$ Films. Chem. Commun. 2002, 14, 1464-1465. [CrossRef]

9. Bhattacharya, S.; Pal, A.; Jana, A.; Datta, J. Synthesis and Characterization of CdS Canoparticles Decorated $\mathrm{TiO}_{2}$ Matrix for an Efficient N3 Based Dye Sensitized Solar Cell (DSSC). J. Mater. Sco. Mater. Electron. 2016, 27, 12438-12445. [CrossRef]

10. Yue, G.; Wu, J.; Xiao, Y.; Lin, J.; Huang, M.; Fan, L.; Yao, Y. A Dye-Sensitized Solar Cell Based on PEDOT: PSS Counter Electrode. Chin. Sci. Bull. 2013, 58, 559-566. [CrossRef]

11. Kakiage, K.; Aoyama, Y.; Yano, T.; Oya, K.; Fujisawa, J.-I.; Hanaya, M. Highly-Efficient Dye-Sensitized Solar Cells With Collaborative Sensitization by Silyl-Anchor and Carboxyl-Anchor Dyes. Chem. Commun. 2015, 51, 15894-15897. [CrossRef] [PubMed]

12. Lee, Y.; Kang, M. The Optical Properties of Nanoporous Structured Titanium Dioxide and the Photovoltaic Efficiency on DSSC. Mater. Chem. Phys. 2010, 122, 284-289. [CrossRef]

13. Fang, X.; Li, M.; Guo, K.; Li, J.; Pan, M.; Bai, L.; Luoshan, M.; Zhao, X. Graphene Quantum Dots Optimization of Dye-Sensitized Solar Cells. Electrochim. Acta 2014, 137, 634-638. [CrossRef]

14. Gong, J.; Sumathy, K.; Qiao, Q.; Zhou, Z. Review on Dye-Sensitized Solar Cells (DSSCs): Advanced Techniques and Research Trends. Renew. Sustain. Energy Rev. 2017, 68, 234-246. [CrossRef]

15. Wang, L.; Jia, L.; Li, Q. A Novel Sulfur Source for Biosynthesis of (Ag, S)-Modified $\mathrm{TiO}_{2}$ Photoanodes in DSSC. Mater. Lett. 2014, 123, 83-86. [CrossRef]

16. Jeong, H.; Lee, Y.; Kim, Y.; Kang, M. Enhanced Photoelectric Efficiency by Surface Modification of $\mathrm{TiO}_{2} \mathrm{Thin}$ Film Using Various Acidic Species. Korean J. Chem. Eng. 2010, 27, 1462-1468. [CrossRef]

17. Jin, E.M.; Zhao, X.G.; Park, J.-Y.; Gu, H.-B. Enhancement of the Photoelectric Performance of Dye-Sensitized Solar Cells Using Ag-doped $\mathrm{TiO}_{2}$ Nanofibers in a $\mathrm{TiO}_{2}$ Film as Electrode. Nanoscale Res. Lett. 2012, 7, 97. [CrossRef]

18. Shakir, S.; Abd-ur-Rehman, H.M.; Yunus, K.; Iwamoto, M.; Periasamy, V. Fabrication of Un-Doped and Magnesium Doped $\mathrm{TiO}_{2}$ Films by Aerosol Assisted Chemical Vapor Deposition for Dye Sensitized Solar Cells. J. Alloy. Compd. 2018, 737, 740-747. [CrossRef]

19. Supriyanto, A.; Furqoni, L.; Nurosyid, F.; Hidayat, J.; Suryana, R. Effect of Sintering Temperatures and Screen Printing Types on $\mathrm{TiO}_{2}$ Layers in DSSC Applications. AIP Conf. Proc. 2016, 1717, 040001. [CrossRef]

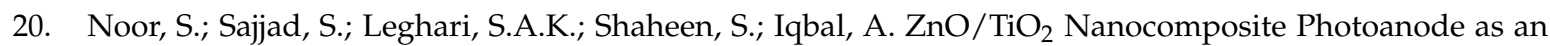
Effective UV-vis Responsive Dye Sensitized Solar Cell. Mater. Res. Express 2018, 5, 095905. [CrossRef]

21. Hamadanian, M.; Safaei-Ghomi, J.; Hosseinpour, M.; Masoomi, R.; Jabbari, V. Uses of New Natural Dye Photosensitizers in Fabrication of High Potential Dye-Sensitized Solar Cells (DSSCs). Mater. Sci. Semicond. Process. 2014, 27, 733-739. [CrossRef]

22. Cho, J.S.; Hong, Y.J.; Kang, Y.C. Electrochemical Properties of Fiber-in-Tube-and Filled-Structured $\mathrm{TiO}_{2}$ Nanofiber Anode Materials for Lithium-Ion Batteries. Chem.-Eur. J. 2015, 21, 11082-11087. [CrossRef]

23. Jin, E.M.; Park, J.-Y.; Hwang, K.-J.; Gu, H.-B.; Jeong, S.M. Biotemplated Hybrid $\mathrm{TiO}_{2}$ Nanoparticle and $\mathrm{TiO}_{2}-\mathrm{SiO}_{2}$ Nanocomposites for Dye-Sensitized Solar Cells. Mater. Lett. 2014, 131, 190-193. [CrossRef]

24. Desai, U.V.; Xu, C.; Wu, J.; Gao, D. Hybrid $\mathrm{TiO}_{2}-\mathrm{SnO}_{2}$ Nanotube Arrays for Dye-Sensitized Solar Cells. J. Phys. Chem. C 2013, 117, 3232-3239. [CrossRef]

25. Luan, X.; Wang, Y. Ultrathin Exfoliated $\mathrm{TiO}_{2}$ Nanosheets Modified with $\mathrm{ZrO}_{2}$ for Dye-Sensitized Solar Cells. J. Phys. Chem. C 2014, 118, 18917-18923. [CrossRef]

26. Jin, E.M.; Park, J.-Y.; Gu, H.-B.; Jeong, S.M. Synthesis of $\mathrm{SnO}_{2}$ Hollow Fiber Using Kapok Biotemplate for Application in Dye-Sensitized Solar Cells. Mater. Lett. 2015, 159, 321-324. [CrossRef]

27. Swathy, K.S.; Abraham, P.A.; Panicker, N.R.; Pramanik, N.C.; Jacob, K.S. Nanostructured Anatase Titania Spheres as Light Scattering Layer in Dye-Sensitized Solar Cells. Procedia Technol. 2016, 24, 767-773. [CrossRef]

28. Shabdan, Y.; Ronasi, A.; Coulibaly, P.; Moniruddin, M.; Nuraje, N. Engineered Core-Shell Nanofibers for Electron Transport Study in Dye-Sensitized Solar Cells. AIP Adv. 2017, 7, 065008. [CrossRef]

29. Wang, H.; Wang, B.; Yu, J.; Hu, Y.; Xia, C.; Zhang, J.; Liu, R. Significant Enhancement of Power Conversion Efficiency for Dye Sensitized Solar Cell Using 1D/3D Network Nanostructures as Photoanodes. Sci. Rep. 2015, 5, 9305. [CrossRef] 
30. Weintraub, B.; Wei, Y.; Wang, Z.L. Optical Fiber/Nanowire Hybrid Structures for Efficient Three-Dimensional Dye-Sensitized Solar Cells. Angew. Chem. Int. Ed. 2009, 121, 9143-9147. [CrossRef]

31. Ding, Y.; Zhou, L.; Mo, L.; Jiang, L.; Hu, L.; Li, Z.; Chen, S.; Dai, S. TiO 2 Microspheres with Controllable Surface Area and Porosity for Enhanced Light Harvesting and Electrolyte Diffusion in Dye-Sensitized Solar Cells. Adv. Funct. Mater. 2015, 25, 5946-5953. [CrossRef]

32. Ruqaishy, M.A.; Marzouqi, F.A.; Qi, K.; Liu, S.-Y.; Karthikeyan, S.; Kim, Y.; Al-Kindy, S.M.Z.; Kuvarega, A.T.; Selvaraj, R. Template-Free Preparation of $\mathrm{TiO}_{2}$ Microspheres for the Photocatalytic Degradation of Organic Dye. Korean J. Chem. Eng. 2018, 35, 2283-2289. [CrossRef]

33. Choi, J.; Yoo, K.S.; Kim, J. Spray Pyrolysis Synthesis of Mesoporous $\mathrm{TiO}_{2}$ Microspheres and Their Post Modification for Improved Photocatalytic Activity. Korean J. Chem. Eng. 2018, 35, 2480-2486. [CrossRef]

34. Park, N.-G.; Schlichthörl, G.; Van de Lagemaat, J.; Cheong, H.M.; Mascarenhas, A.; Frank, A.J. Dye-Sensitized $\mathrm{TiO}_{2}$ Solar Cells: Structural and Photoelectrochemical Characterization of Nanocrystalline Electrodes Formed from the Hydrolysis of $\mathrm{TiCl}_{4}$. J. Phys. Chem. B 1999, 103, 3308-3314. [CrossRef]

35. Liu, L.; Niu, H.; Zhang, S.Z.; Wan, L.; Miao, S.; Xu, J. Improved Performance of Dye-Sensitized Solar Cells: An $\mathrm{TiO}_{2}-\mathrm{Nano}-\mathrm{SiO}_{2}$ Hybrid Photoanode with Post-Treatment of $\mathrm{TiCl}_{4}$ Aqueous Solution. Appl. Surf. Sci. 2012, 261, 8-13. [CrossRef]

(C) 2019 by the authors. Licensee MDPI, Basel, Switzerland. This article is an open access article distributed under the terms and conditions of the Creative Commons Attribution (CC BY) license (http:/ / creativecommons.org/licenses/by/4.0/). 